\title{
Netrin-1/DCC Signaling in Commissural Axon Guidance Requires Cell-Autonomous Expression of Heparan Sulfate
}

\author{
Yoshihiro Matsumoto, ${ }^{1}$ Fumitoshi Irie, ${ }^{1,2}$ Masaru Inatani, ${ }^{1}$ Marc Tessier-Lavigne, ${ }^{3}$ and Yu Yamaguchi ${ }^{1,2}$ \\ ${ }^{1}$ Developmental Neurobiology and ${ }^{2}$ Glycobiology Programs, Burnham Institute for Medical Research, La Jolla, California 92037, and ${ }^{3}$ Genentech, South San \\ Francisco, California 94080
}

\begin{abstract}
There is increasing evidence that heparan sulfate (HS) plays an essential role in various axon guidance processes. These observations, however, have not addressed whether HS is required cell autonomously as an axonal coreceptor or as an environmental factor that modulates the localization of guidance molecules in the terrain in which growing axons navigate. Here we demonstrate that netrin-1mediated commissural axon guidance requires cell-autonomous expression of HS in commissural neurons in vivo. We used the Wnt1 -Cre transgene to drive region-specific ablation of Ext1, which encodes an enzyme essential for HS synthesis, in the dorsal part of the spinal cord. Remarkably, Wnt1-Cre-mediated ablation of Ext1 causes commissural axon pathfinding defects that share similarities with those of Netrin-1-deficient and DCC (deleted in colorectal cancer)-deficient mice. Neither Ext1-deficient dorsal spinal cord explants nor wild-type explants in which HS expression was ablated could extend axons in response to netrin-1. Intracellular signaling downstream of netrin-1 and DCC was defective in Ext1-deficient commissural neurons and in DCC-transfected HEK293T cells from which HS was removed. These results demonstrate that the expression of HS by commissural neurons is essential for these neurons to transduce netrin-1 signals, thus providing evidence for a cell-autonomous role of HS in netrin-1/DCC-mediated axon guidance.
\end{abstract}

Key words: heparan sulfate; Ext1; netrin-1; DCC; spinal cord; axon guidance

\section{Introduction}

Heparan sulfate (HS), one of the four classes of glycosaminoglycans, plays critical roles in many developmental processes through their interactions with morphogens (Lander and Selleck, 2000; Perrimon and Bernfield, 2000; Esko and Lindahl, 2001). Recent genetic studies in mice and lower species of model animals have revealed that HS is also functionally critical for various axon guidance processes (Lee and Chien, 2004; Holt and Dickson, 2005). For instance, conditional ablation of HS synthesis in the developing mouse CNS (by way of disrupting Ext1; see below) results in defects in multiple axon pathfinding processes, including retinal axon guidance at the optic chiasm and the development of the fasciculus retroflexus (Inatani et al., 2003; Kantor et al., 2004). Despite this progress, not much is known about the mechanisms by which HS is involved in these axon guidance processes.

In this study, we examined the role and mechanism of action of HS in the pathfinding of spinal cord commissural axons. Axons from commissural neurons, which reside in the most dorsal part of the spinal cord, project ventrally toward the ventral midline. They then cross the midline and turn rostrally to project longitudinally in the ventral funiculus (Bovolenta and Dodd,

Received Sept. 8, 2006; accepted March 12, 2007.

This work was supported by National Institutes of Health Grants NS41332 and HD25938. We thank Dr. A. P. McMahon for his gift of Wnt1-Cre mice and in situ hybridization probes, Dr. A. Oohira for his gift of anti-syndecan-3 antibody, Dr. J. Esko for his gift of xylosides, and Dr. W. B. Stallcup for reading this manuscript.

Correspondence should be addressed to Yu Yamaguchi, Burnham Institute for Medical Research, 10901 North Torrey Pines Road, La Jolla, CA 92037. E-mail: yyamaguchi@burnham.org.

DOI:10.1523/JNEUROSCI.0700-07.2007

Copyright $\odot 2007$ Society for Neuroscience $\quad$ 0270-6474/07/274342-09\$15.00/0
1990). The initial trajectory of commissural axons toward the ventral midline is controlled primarily by the long-range chemoattractant netrin-1, which is secreted from the floor plate (Kennedy et al., 1994). Netrin-1 binds to the transmembrane protein DCC (deleted in colorectal cancer) expressed on the growth cones of commissural axons, triggering intracellular signaling that leads to attraction of the growth cone along the netrin-1 gradient (Keino-Masu et al., 1996). The fundamental importance of the netrin-1/DCC system in commissural axon guidance has been demonstrated by the phenotypes of both Netrin-1 $1^{-/-}$and $D c c^{-/-}$mice (Serafini et al., 1996; Fazeli et al., 1997). Interestingly, netrin-1 is known to bind to heparin (Serafini et al., 1994). Moreover, DCC also has affinity for heparin (Bennett et al., 1997). Thus, commissural axon pathfinding is a process in which the physiological involvement of $\mathrm{HS}$ is predicted.

To examine and dissect the role of HS in this process, we used a conditional Ext1 null allele (Inatani et al., 2003). Ext1 encodes a glucuronic acid/N-acetylglucosamine copolymerase that is essential for HS synthesis (Zak et al., 2002). Using the Wnt1-Cre transgene, we ablated Ext1 specifically in the dorsal spinal cord, in which the cell bodies of commissural neurons reside, without altering HS expression in the ventral spinal cord in which growing commissural axons navigate. These conditional knock-out mice exhibited commissural axon guidance defects that share remarkable similarities with those found in Netrin-1 $1^{-/-}$and $\mathrm{Dcc}^{-1-}$ mice. Moreover, we found that both the in vitro axon outgrowth response and intracellular signaling downstream of netrin-1 and DCC are disrupted in mutant commissural neurons. Thus, HS needs to be expressed by commissural neurons for 
their axons to respond to netrin-1. Our results provide definitive evidence for a cell-autonomous requirement for HS in netrin-1mediated axon guidance and netrin-1/DCC signaling.

\section{Materials and Methods}

Mouse strains. Mutant mouse strains used in this study have all been reported previously (Danielian et al., 1998; Soriano, 1999; Tronche et al., 1999; Inatani et al., 2003). To produce Wnt1-Cre-driven Ext1 conditional mutant mice, Wnt1-Cre transgenic mice were mated with heterozygous mice carrying the Ext flox allele. Subsequently, they were mated with mice homozygous for the Ext flox $^{\text {flo }}$ allele $\left(\right.$ Ext $\left.1^{\text {flox/flox }}\right)$ to obtain embryos with a Wnt1-Cre; Ext $1^{\text {floxfllox }}$ genotype. Littermates that inherited the incomplete combination of the above alleles were used as controls (referred to as wild type). Genotyping of the animals was done by PCR using DNA prepared from tail biopsies. All protocols for animal use were approved by the Institutional Animal Care and Use Committee of the Burnham Institute for Medical Research and were in accordance with National Institutes of Health guidelines.

Cell culture. Commissural neurons were dissociated from embryonic day 11.5 (E11.5) dorsal spinal cords and cultured on laminin-coated dishes in serum-free Neurobasal medium (Invitrogen, Carlsbad, CA) supplemented with B27 (Invitrogen) as described previously (Bouchard et al., 2004). Neurons from the ventral spinal cords were cultured in the same manner. For immunocytochemistry, cultures at $2 \mathrm{~d}$ in vitro were incubated live with the 10E4 anti-HS monoclonal antibody (mouse IgM; Seikagaku America, Rockville, $\mathrm{MD}$ ) for $1 \mathrm{~h}$ in a $\mathrm{CO}_{2}$ incubator. Cells were then fixed in $4 \%$ paraformaldehyde (PFA) for $10 \mathrm{~min}$ at room temperature and permeabilized in $0.2 \%$ Trion X-100 for $10 \mathrm{~min}$ at $4^{\circ} \mathrm{C}$. Cells were incubated with monoclonal anti-DCC (mouse IgG; PharMingen, San Diego, CA) and rabbit polyclonal anti-neurofilament (NF) (Chemicon, Temecula, CA) antibodies for $2 \mathrm{~h}$ at room temperature, followed by detection with Alexa 488 anti-mouse IgM (Invitrogen), rhodamine red-X anti-mouse IgG (Jackson ImmunoResearch, West Grove, PA), and cyanine 5 anti-rabbit IgG (Jackson ImmunoResearch).

Histological and immunohistochemical analyses. For hematoxylin-eosin (HE) staining, embryos were fixed in 4\% PFA in PBS, washed in PBS, dehydrated, and embedded in paraffin. For immunohistochemistry, PFA-fixed cryostat sections were stained with anti-neurofilament (3A10), anti-TAG-1 (transient axonal glycoprotein 1), anti-Pax7 (paired box gene 7), anti-En1 (Engrailed 1), and anti-Nkx2.2 (NK2 transcription factor-related 2.2) (Developmental Studies Hybridoma Bank, University of Iowa, Iowa City, IA). To quantify the size of the ventral commissure, the thickness of the commissure was measured in three sections per embryo and averaged. NIH ImageJ software was used for the measurement. In situ hybridization with digoxigenin-labeled riboprobes was performed on cryosections as described previously (Inatani et al., 2003). For DiI tracing of commissural axons, embryos at E11.5 were fixed in $4 \%$ PFA overnight, and crystals of DiI (Invitrogen) were implanted on the dorsal part of spinal cord for $24 \mathrm{~h}$. Vibratome sections were cut and examined on a fluorescent microscope. $\beta$-Galactosidase ( $\beta$-gal) staining of the Wnt1-Cre;R26R (ROSA26 reporter) embryos was performed as described previously (Yu et al., 2003).

Explant assays. E11.5 dorsal spinal cord explants were dissected as described previously (Kennedy et al., 1994). For coculture assays, explants were cultured for $24 \mathrm{~h}$ in three-dimensional collagen gels (type I; BD Biosciences, San Jose, CA) with aggregates of netrin-1-expressing HEK293T cells according to Del Rio et al. (2004). Transient transfection of HEK293T cells with netrin-1 was performed using Lipofectamine 2000 (Invitrogen). To test the effect of purified netrin-1, explants embedded in collagen gels were cultured with recombinant netrin-1 (R \& D Systems, Minneapolis, MN) in combination with enzymatic and chemical removal of HS. Explants were incubated for $3 \mathrm{~h}$ with or without $2 \mathrm{U} / \mathrm{ml}$ heparitinase, $20 \mu \mathrm{M}$ naphthol- $\beta$-D-xyloside (Xyl-naphthol), or $20 \mu \mathrm{M}$ decahydro-2-naphthol- $\beta$-D-xyloside (Xyl-decalin), and then concentrated recombinant netrin- 1 was added to culture media at a final concentration of $500 \mathrm{ng} / \mathrm{ml}$. Explants were then cultured for $24 \mathrm{~h}$. Images were captured with a digital camera mounted on a microscope with a phase-contrast objective. The total lengths of axon bundles were measured using NIH ImageJ software.

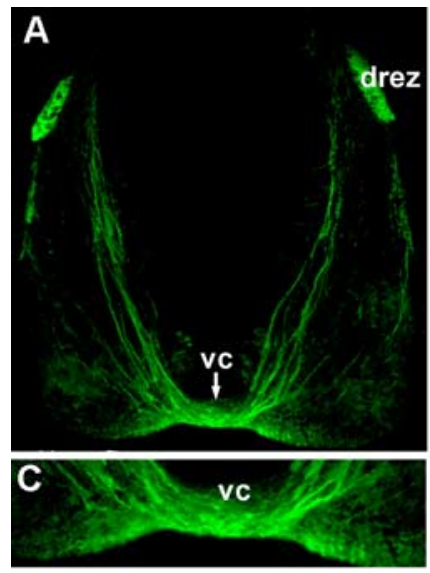

wild type
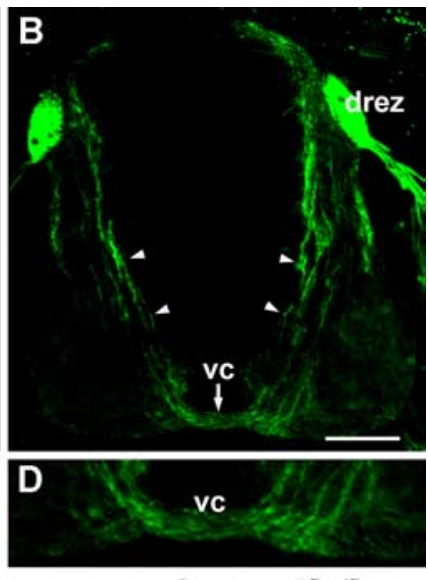

Nestin-Cre;Ext $1^{\text {floxfllox }}$
Figure 1. Commissural axon phenotypes in Nestin-Cre; Ext f floxfflox embryos. A-D, Transverse sections of E11.5 Nestin-Cre; Ext $7^{\text {flox }}$ fllox $(\boldsymbol{B}, \boldsymbol{D})$ and wild-type littermate $(\boldsymbol{A}, \boldsymbol{C})$ embryos were stained with anti-TAG-1 antibody. drez, Dorsal root entry zone; vc, ventral commissure. Note that, in wild-type mice, $\mathrm{TAG}-1^{+}$commissural axons extend in a highly fasciculated manner and form a thick ventral commissure, whereas in Nestin-Cre; Ext $7^{\text {flox/flox }}$ mice, commissural axons show defasciculation (arrowheads in $\boldsymbol{B}$ ), and the size and staining intensity of the ventral commissure are reduced. Scale bar, $100 \mu \mathrm{m}$.

Biochemical and immunochemical analyses. For the analysis of syndecan-3 glycanation, spinal cords were dissected into dorsal and ventral parts, separately homogenized, and lysed in radioimmunoprecipitation assay (RIPA) buffer. For heparitinase treatment of lysates, whole spinal cord of wild-type embryos were homogenized in 10 mM HEPES buffer, pH 7.2, containing $1 \mathrm{~mm}$ calcium acetate and incubated with heparitinase as described previously (Inatani et al., 2003). Lysates were immunoblotted with anti-syndecan-3 polyclonal antibody (Toba et al., 2002). For the analysis of extracellular signal-regulated kinase (ERK) activation, cells (dissociated commissural neurons and HEK293T cells transfected with myc-tagged DCC; see below) were treated with 500 $\mathrm{ng} / \mathrm{ml}$ recombinant netrin-1 for $15 \mathrm{~min}$ and lysed in SDS sample buffer. Lysed samples were resolved by SDS-PAGE and subjected to immunoblotting with anti-ERK1/2 and anti-phospho-ERK1/2 antibodies (Cell Signaling Technology, Beverly, MA). For the analysis of DCC phosphorylation in spinal cords, dissected dorsal spinal cords were homogenized and lysed in RIPA buffer. Lysed samples were immunoprecipitated with anti-DCC antibody (PharMingen) and then immunoblotted with antiDCC and anti-phosphotyrosine (clone PY-20; Transduction Laboratories, Lexington, KY) antibodies. For the analysis of DCC phosphorylation in HEK293T cells, cells stimulated with netrin-1 as described above were lysed in RIPA buffer, immunoprecipitated with anti-myc monoclonal antibody (9E10; Santa Cruz Biotechnology, Santa Cruz, CA), and immunoblotted with PY-20. To express myc-tagged DCC, HEK293T cells were transfected with rat DCC cDNA ligated to pcDNA3.1/myc-His using Lipofectamine 2000. Quantification of immunoblotting results was performed by densitometric analysis as described previously (Irie et al., 2005).

\section{Results}

\section{Cre-mediated ablation of Ext 1 in the spinal cord}

We used two different conditional gene ablation paradigms to analyze the role of HS in the guidance of spinal commissural axons. First, we generated conditional Ext1 mutants driven by the Nestin-Cre transgene (Tronche et al., 1999), as described previously (Inatani et al., 2003). This Cre transgene drives recombination in the spinal cord starting at approximately E10.5, and, by E11.5, recombination occurs in the entire spinal cord (Kramer et al., 2006). In Nestin-Cre;Ext1 $1^{\text {flox/flox }}$ embryos, we found that the size of the ventral commissure was mildly reduced and that commissural axons were somewhat defasciculated (Fig. 1), suggesting 
a role for HS in commissural axon guidance. This phenotype, however, was by no means striking. One explanation for this mild phenotype is that the onset of commissural axon elongation, which occurs at approximately E9.5 (Colamarino and Tessier-Lavigne, 1995), precedes NestinCre-mediated Ext1 ablation. We therefore suspected that the observed phenotype under-represents the functional significance of HS in netrin-1-mediated commissural axon guidance.

To test this possibility, we used the Wnt1Cre transgene (Danielian et al., 1998). In the mouse spinal cord, Wnt1-Cre-mediated recombination begins at E9.5 and occurs selectively in the most dorsal part of the spinal cord, in which cell bodies of commissural neurons are located (Charron et al., 2003). We confirmed the reported spatial pattern of Wnt1-Cre-driven recombination using ROSA26 reporter $(R 26 R)$ mice (Soriano, 1999) (Fig. 2A-C).

We then generated conditional null embryos (Wnt1-Cre;Ext1 $1^{\text {flox/flox }}$ ) and examined whether HS synthesis is indeed abolished specifically in the dorsal spinal cord. First, we examined glycanation of syndecan-3, which is one of the most abundant HS proteoglycans (HSPGs) in the developing nervous system and can be used as a sensitive general marker for the glycanation status of HSPGs (Inatani et al., 2003). Separate tissue lysates were prepared from the dorsal and ventral spinal cord and immunoblotted with antisyndecan-3 antibody (Toba et al., 2002). In the ventral spinal cord of the E11.5 Wnt1-Cre;Ext1 $1^{\text {flox/flox }}$ mice, syndecan-3 was detected as a high-molecular-weight smear (Fig. 2 D, lane 2), similar to that seen in the wild-type spinal cord (lane 1), indicating that, in the ventral spinal cord of Wnt1-Cre; Ext $1^{\text {flox/flox }}$ mice, syndecan-3 is glycanated by HS normally. In contrast, syndecan-3 in the dorsal spinal cord of Wnt1-Cre;Ext $1^{\text {flox/flox }}$ mice was detected as a single, low-molecular-weight band (lane 3 ), which shows the same mobility with heparitinase-digested syndecan-3 from wild-type spinal cord (lane 5). This indicates that syndecan-3 is expressed without HS chains in the mutant dorsal spinal cord. Thus, HS synthesis is abolished in a regionspecific manner, as expected from the spatial specificity of the Wnt1-Cre transgene.

Second, we examined by immunocytochemistry whether HS expression is indeed ablated in commissural neurons. Neurons were dissociated from the dorsal and ventral spinal cords of E11.5 mutant and wild-type embryos and immunostained with antiHS, anti-DCC, and anti-NF antibodies. Neurons dissociated from the wild-type dorsal spinal cord were immunoreactive to anti-HS antibody (Fig. 3A, row a). These neurons were also immunoreactive to anti-DCC antibody, indicating that they are commissural neurons. In contrast, DCC-positive $\left(\mathrm{DCC}^{+}\right)$neurons from the mutant dorsal spinal cord were not immunoreactive to anti-HS antibody (Fig. $3 A$, row b, $B$ ). Quantification of
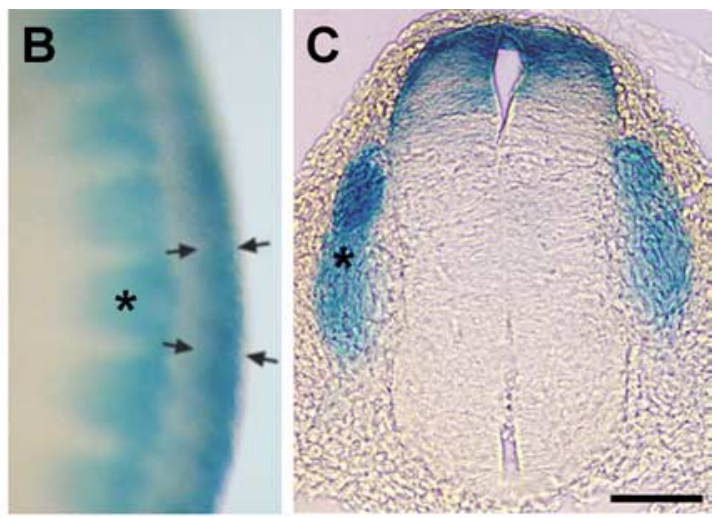

Figure 2. Dorsal spinal cord-specific ablation of HS synthesis in Wnt1-Cre; Ext $7^{\text {flox fllox }}$ mice. A-C, Spatial extent of Wnt1-Cremediated gene recombination. Wnt1-Cre;R26R embryos were stained for $\beta$-gal activity. A, Wnt1-Cre;R26R whole embryo at E11.5. $\boldsymbol{B}$, Enlarged view of the rectangle in $\boldsymbol{A}$. Note that recombination is restricted in the dorsal part of the spinal cord (indicated a syndecan-3 were analyzed by immunoblotting with lysates from the dorsal and ventral parts of E11.5 spinal cords. Lane 1, Syndecan-3 in the whole spinal cord of wild-type mice; lane 2, syndecan-3 in the ventral part of the Wnt 1 -Cre; Ext flox $^{\text {flox }}$ spinal cord; lane 3, syndecan-3 in the dorsal part of the Wnt1-Cre; Ext $7^{f l o x}$ flox spinal cord; lane 4, syndecan-3 in the whole spinal cord of in wild-type spinal cord (arrows). Syndecan-3 in the mutant ventral spinal cord shows a high-molecular-weight smear (vertical bars), indicating a fully glycanated form. Bands indicated by an asterisk are nonspecific.

immunoreactivity shows that these neurons from the mutant dorsal spinal cords express normal levels of DCC (Fig. 3C) and TAG-1 (data not shown). Neurons from the ventral part of the mutant spinal cord were immunoreactive to anti-HS (Fig. $3 A$, row $\mathrm{d}$ ), as those dissociated from the wild-type ventral spinal cord (Fig. 3A, row c). Together, these results confirm that, consistent with the spatiotemporal recombination pattern of the Wnt1-Cre transgene, HS expression is abolished selectively in the dorsal spinal cord (and in commissural neurons), whereas HS expression in the ventral spinal cord is unperturbed.

Histological analysis demonstrates that the overall morphology of the spinal cord in Wnt1-Cre; Ext flox/flox embryos is normal, except for the ventral commissure (see below). Moreover, no significant differences in the expression of Pax7, En1, Nkx2.2, Shh (Sonic hedgehog), and Ptc (Patched) were observed (Fig. 4), indicating that the overall patterning of the spinal cord was not perturbed in these embryos.

Commissural axon phenotypes in Wnt1-Cre;Ext $1^{\text {flox/flox }}$ mice To assess the effect of Ext1 ablation on commissural axon pathfinding, we examined the developing spinal cord of Wnt1-Cre; Ext $1^{\text {flox/flox }}$ embryos. Standard histological preparations revealed 


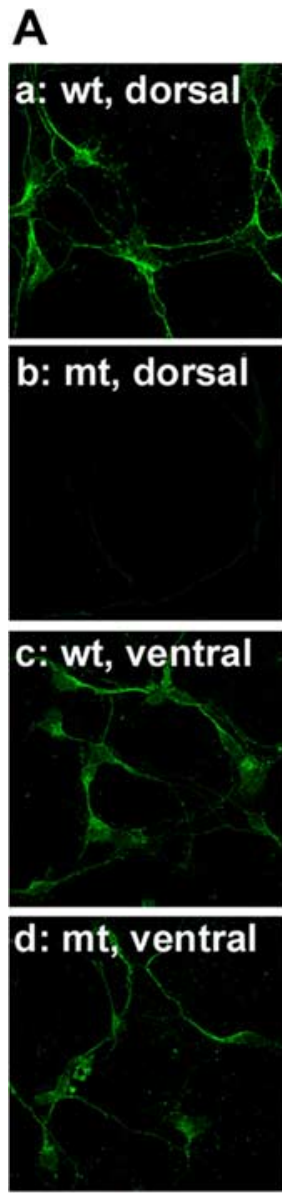

HS
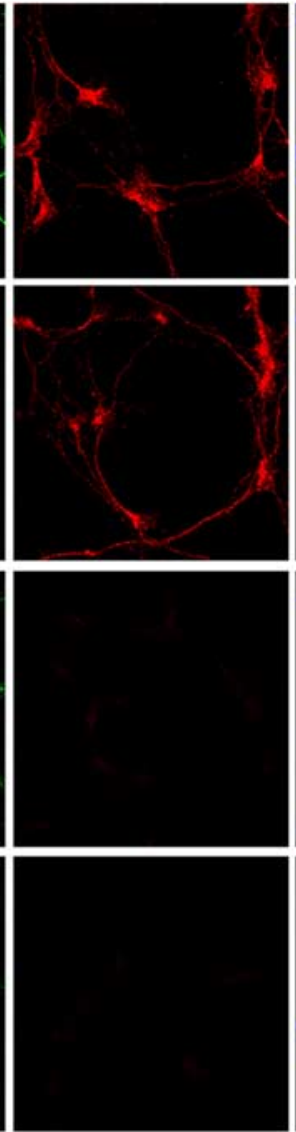

DCC
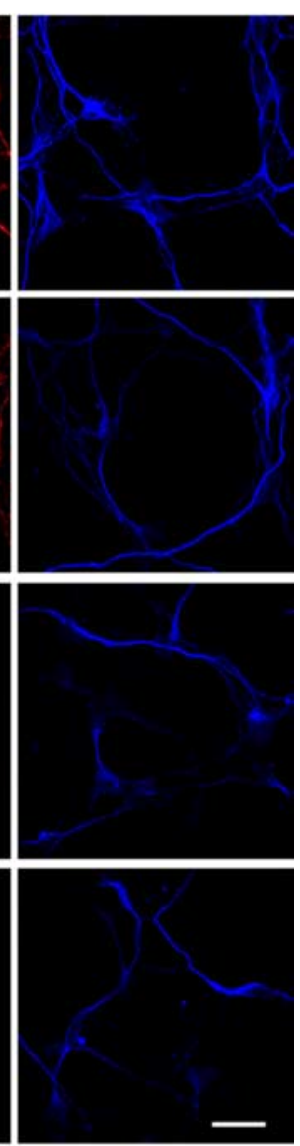

NF
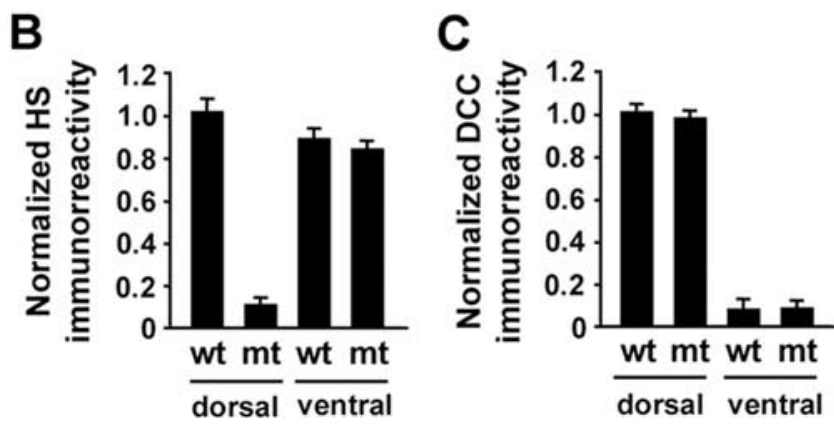

Figure 3. Immunocytochemical analysis of commissural neurons dissociated from Wnt1Cre; Ext $f^{\text {flox/flox }}$ mice. $A$, Neurons were dissociated, separately, from the dorsal and ventral spinal cords of E11.5 Wnt1-Cre;Ext $1^{\text {flox/flox }}$ and wild-type embryos and triple-stained with anti-HS (HS), anti-DCC (DCC), and anti-neurofilament $150 \mathrm{kDa}$ (NF) antibodies at $2 \mathrm{~d}$ in vitro. Row a, Wild-type, dorsal; row b, mutant, dorsal; row c, wild-type, ventral; row d, mutant, ventral. Scale bar, $20 \mu \mathrm{m}$. B, C, Quantification of expression levels of HS $(\boldsymbol{F})$ and DCC $(\boldsymbol{G})$ in neurons dissociated from the ventral and dorsal spinal cords. mt, Wnt1-Cre;Ext7 $7^{\text {flox/flox; }}$; wt, wild type. Intensity of anti-HS and anti-DCC immunoreactivities was measured by image analysis (mean $\pm S D ; n=16$ ).

that the ventral commissure of the spinal cord is greatly reduced in Wnt1-Cre;Ext1 $1^{\text {flox/flox }}$ embryos (Fig. 5D). Quantification of the thickness of the ventral commissure confirmed a consistent reduction of the ventral commissure in Wnt1-Cre;Ext1 $1^{\text {flox/flox }}$ embryos [wild type $(n=4), 17.8 \pm 0.5 \mu \mathrm{m} ;$ Wnt1-Cre;Ext $1^{\text {flox/flox }}$ $(n=4), 6.6 \pm 0.6 \mu \mathrm{m}]$. Immunohistochemical analysis with anti-NF (Fig. 5E-H) and anti-TAG-1 (Fig. 5I-L) antibodies also demonstrates the greatly reduced ventral commissure. Again, quantification confirmed a consistent reduction of axons crossing the ventral midline [for anti-NF immunostaining: wild type $(n=4), 17.8 \pm 0.9 \mu \mathrm{m} ;$ Wnt1-Cre; Ext $1^{\text {flox/flox }}(n=4), 8.3 \pm 0.6$ $\mu \mathrm{m}$; for anti-TAG-1 immunostaining: wild-type $(n=4), 17.0 \pm$ $0.7 \mu \mathrm{m} ;$ Wnt1-Cre;Ext1 $\left.1^{\text {flox/flox }}(n=4), 6.2 \pm 0.5 \mu \mathrm{m}\right]$. This ventral commissure phenotype is similar to that reported for $\mathrm{Ne}$ trin $^{-1-}$ (Serafini et al., 1996) and $\mathrm{Dcc}^{-/-}$(Fazeli et al., 1997) mice. Immunostaining with anti-NF antibody revealed that ventrally directed axons in the wild-type embryos (Fig. 5E, arrowheads) are disturbed and reduced in Wnt1-Cre; Ext $1^{\text {flox/flox }} \mathrm{em}$ bryos (Fig. $5 F$ ). Immunostaining with anti-TAG-1 antibody, which selectively labels commissural axons, also demonstrates abnormal commissural axon trajectories. In addition to the reduction of ventrally directed TAG- $1^{+}$axons and axons crossing the midline (Fig. $5 \mathrm{~J}, L$ ), misrouting of TAG $-1^{+}$axons around and into the motor column was consistently observed (Fig. 5J, arrows).

Abnormal commissural axon trajectories were also demonstrated by whole-mount immunostaining of the spinal cord in an open-book configuration and by anterograde tracing via DiI incorporation into the dorsal spinal cord. The sagittal view of whole-mount hemicords stained with anti-TAG-1 revealed a marked reduction of commissural axons reaching the ventral commissure in mutant embryos (Fig. 6B). Axon tracing experiments with DiI demonstrated that, in mutant embryos, few commissural axons project along the normal trajectory (Fig. 6D). The majority of commissural axons project along the lateral edge of the motor column. Together, although there are minor differences in the severity and pattern of the phenotype, these commissural axon defects in Wnt1-Cre;Ext $1^{\text {flox/flox }}$ mice share remarkable similarities with those of Netrin-1 ${ }^{-/-}$(Serafini et al., 1996) and $\mathrm{Dcc}^{-/-}$(Fazeli et al., 1997) mutant mice, which suggests a physiological requirement for HS in netrin-1-mediated axon guidance. Furthermore, it is intriguing that this phenotype emerged when HS expression was abolished selectively in the dorsal spinal cord but not in the ventral spinal cord. This suggests that HS needs to be autonomously expressed by commissural neurons for their axons to respond to netrin-1 signals.

HS expression is required for commissural axon outgrowth in response to netrin-1 in vitro

To obtain additional evidence for the requirement of cellautonomous expression of HS, we analyzed the ability of dorsal spinal cord explants to extend axons in response to exogenous netrin-1. We examined axon outgrowth responses using explant cocultures in collagen gels (Tessier-Lavigne et al., 1988). In these experiments, dorsal spinal cord explants from wild-type and mutant embryos were cocultured with aggregated HEK293T cells producing netrin-1. Wild-type explants cocultured with netrin1-producing cells showed robust axon outgrowth (Fig. $7 B, E$ ). In contrast, explants from Wnt1-Cre; Ext $1^{\text {flox/flox }}$ embryos failed to extend axons in response to netrin-1-producing cells (Fig. $7 D, E$ ).

To further investigate the requirement of HS in netrin-1 action, we performed experiments using purified recombinant netrin-1 in combination with HS removal by enzymatic and chemical treatment. First, wild-type dorsal spinal cord explants were treated with heparitinase. Whereas control-treated explants showed robust axon outgrowth in response to recombinant netrin-1 (Fig. 7G), heparitinase-treated explants showed greatly reduced axon outgrowth (Fig. $7 H$ ). Second, we used chemical inhibitors, namely Xyl-naphthol and Xyl-decalin, to further confirm the requirement of HS on netrin-1 action on axon outgrowth. Xyl-naphthol, which interferes with both HS and chon- 
droitin sulfate (CS) assembly onto proteoglycan core proteins (Fritz et al., 1994), significantly reduced axon outgrowth (Fig. 7J). In contrast, Xyl-decalin, which interferes with CS, but not HS, showed little effects on axon outgrowth (Fig. $7 I$ ). Figure $7 \mathrm{~K}$ summarizes quantitation of these results. Together, these HS removal experiments provide additional evidence for the role for HS in netrin-1dependent axon outgrowth. These results demonstrate that cell-autonomous expression of HS is necessary for commissural neurons to respond to the attractive stimulus of netrin-1.

\section{Effect of the abrogation of HS expression on netrin-1 downstream signaling}

Next, we examined the effect of HS ablation on netrin-1 downstream signaling. One of the consequences of netrin-1 binding to DCC is the activation of the mitogen-activated protein kinase (MAPK) pathway (Forcet et al., 2002). We examined whether this pathway is activated in commissural neurons lacking HS expression. Commissural neurons dissociated from mutant and wild-type embryos were treated with recombinant netrin-1, and cell lysates were analyzed by immunoblot-

ting with anti-phospho-ERK1/2 antibody. In wild-type commissural neurons, treatment with netrin-1 induced a significant ( 2.6-fold over the baseline level) increase in the level of ERK1/2 phosphorylation (Fig. $8 A, B$, wt). In contrast, no increase in netrin-1-dependent ERK phosphorylation was observed in commissural neurons dissociated from Wnt1-Cre;Ext1 flox/flox embryos (Fig. $8 A, B, \mathrm{mt}$ ), suggesting that HS-deficient commissural neurons cannot activate the MAPK pathway in response to netrin-1.

To further characterize the role of HS in this signaling event, we examined the effect of heparitinase treatment on netrin-1dependent ERK activation in DCC-transfected HEK293T cells. Without DCC transfection, netrin-1 did not induce ERK1/2 phosphorylation (Fig. 8C, lane 2), whereas ERK1/2 phosphorylation was induced in DCC-transfected cells (lane 4). Treatment of cells with heparitinase neutralized this effect of netrin-1 stimulation (lane 6). These data demonstrate that netrin-1-dependent ERK activation requires cell surface HS.

Because the MAPK pathway can be activated by a variety of factors, not limited to netrin-1, we examined DCC phosphorylation as a second indicator that is more specific for netrin-1/DCC signaling. It has been shown that netrin-1 induces tyrosine phosphorylation of DCC in commissural neurons and that this phosphorylation is crucial for netrin-1-dependent axon outgrowth function (Meriane et al., 2004). To analyze DCC phosphorylation, HEK293T cells transfected with myc-tagged DCC were treated with netrin-1. Lysates from these cells were immunoprecipitated with anti-myc antibody and then immunoblotted with anti-phosphotyrosine antibody (Fig. 8D). Phosphorylation of DCC was detected in DCC-transfected cells treated with netrin-1 (Fig. 8D, lane 4). Heparitinase treatment almost completely abolished DCC phosphorylation in response to netrin-1 (lane 6).
Next, we examined DCC phosphorylation in the mutant and wild-type spinal cord in vivo. Lysates of E11.5 wild-type and mutant dorsal spinal cords were immunoprecipitated by anti-DCC antibody, and the precipitated material were analyzed by immunoblotting. Immunoblotting with anti-DCC antibody showed that similar levels of DCC are expressed in wild-type and mutant spinal cords (Fig. 8 E, bottom panel), consistent with the results of immunocytochemical analyses (Fig. 3). In wild-type spinal cords, DCC was strongly phosphorylated (left lane, top panel). In contrast, little DCC phosphorylation was detected in Wnt1-Cre; Ext $1^{\text {flox/flox }}$ spinal cords (Fig. $8 E$, right lane, top panel). Thus, DCC is not efficiently phosphorylated in Wnt1-Cre;Ext $11^{\text {flox/flox }}$ mutants in vivo. Together, these results on DCC phosphorylation and MAPK activation demonstrate that expression of HS is necessary for the ability of commissural neurons to transduce netrin-1 signals.

\section{Discussion}

The affinity of netrin-1 for heparin has been noted since the initial biochemical purification of this axon guidance molecule (Kennedy et al., 1994; Serafini et al., 1994). However, the physiological significance of this affinity has long been elusive. Our present study using conditional ablation of HS synthesis in the developing spinal cord confirmed this long-suspected role for HS in netrin-1 function in vivo. The most important and novel aspect of the finding, however, is that HS is required cell autonomously for commissural neurons to respond to the chemoattractive signal of netrin- 1 .

Generally speaking, there are two modes of action of HS in controlling the function of heparin/HS-binding morphogens and growth factors. First, HS in the local environment can modulate the diffusion and/or stability of these factors within the tissue. This mode of action has been extensively studied in the context of 

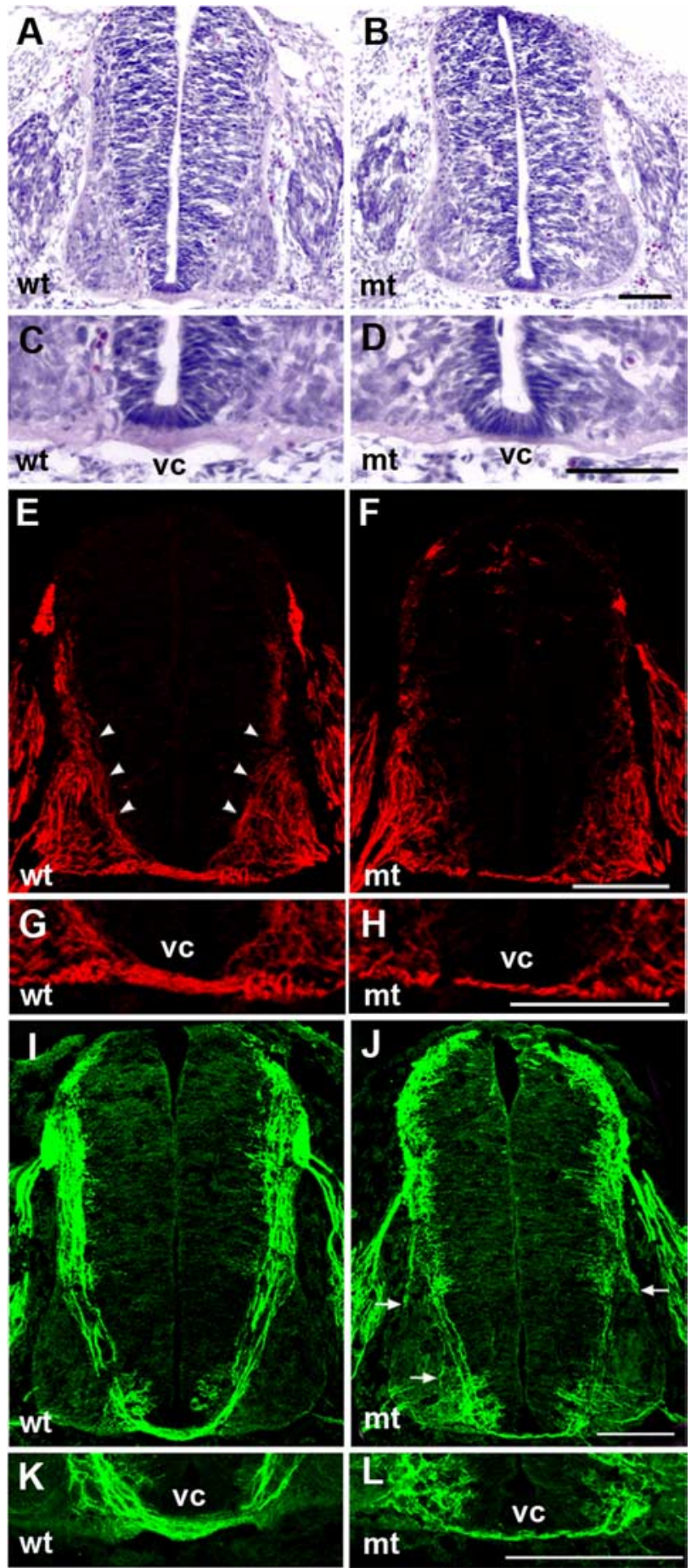

Figure 5. Commissural axon phenotypes of Wnt1-Cre; Ext $7^{\text {flox fllox }}$ mice. mt, Wnt1-Cre; Ext $7^{\text {flox }}{ }^{\text {fflox }}$; wt, control littermate. A-D, Transverse sections of E11.5 spinal cords stained with HE. $\boldsymbol{E}-\boldsymbol{H}$, Transverse sections of E11.5 spinal cords stained with anti-NF antibody. I-L, Transverse sections of E11.5 spinal cords stained with anti-TAG- 1 antibody. Note that the ventral commissure (vc) is greatly reduced $(\boldsymbol{D}, \boldsymbol{H}, \mathbf{L}$; see also the results of quantitative analysis in $\boldsymbol{M}-\mathbf{0})$. Arrowheads in $\boldsymbol{E}$ indicate ventrally directed commissural projection in the wild-type spinal cord, which is disorganized and reduced in mutants $(\boldsymbol{F})$. Misrouted commissural axons projecting around and into the motor column are consistently observed in mutants (arrows in $\boldsymbol{J}$ ). Scale bars, $100 \mu \mathrm{m}$.

morphogen gradient formation during development (The et al., 1999; Fujise et al., 2003; Baeg et al., 2004). Second, cell surface HS can act as a coreceptor for growth factors and morphogens. FGF2 is the prime example in which HSPGs act as obligatory corecep- tors (Rapraeger et al., 1991; Yayon et al., 1991). These two modes of action are not entirely mutually exclusive. Increasing data indicate that some axon guidance molecules also bind HS and require $\mathrm{HS}$ to exert their functions ( $\mathrm{Hu}, 2001$; Inatani et al., 2003; Kantor et al., 2004) (for review, see Lee and Chien, 2004; Holt and Dickson, 2005). Considering that axon guidance occurs in highly defined topological contexts, it is important to determine which mode of HS action is used in the function of these molecules. Cell-autonomous role for HS in guidance signaling has been suggested in the cases of Semaphorin 5A (Kantor et al., 2004) and Slit2 (Pratt et al., 2006), based on the results from in vitro experiments. However, it has been difficult to establish the cellautonomous role of HS in vivo, because HS is usually expressed in both axons and guidepost cells. As demonstrated in this paper, region-specific gene ablation using the Wnt1-Cre transgene provides a powerful approach to address this question. The phenotype of Wnt1-Cre;Ext $1^{\text {flox/flox }}$ mice unambiguously demonstrates that HS needs to be autonomously expressed by commissural neurons for their axons to project correctly toward the ventral midline. Moreover, phenotypical similarities between these mice and Netrin-1 ${ }^{-/-}$and $\mathrm{Dcc}^{-/-}$mice strongly suggest that netrin-1/ DCC signaling functionally requires HS.

Results from our in vitro experiments are consistent with a cell-autonomous role for HS in netrin-1/DCC signaling. Neither dorsal spinal cord explants from Wnt1-Cre;Ext flox/flox embryos nor heparitinase-treated wild-type explants could extend axons in response to netrin-1. We also showed that mutant commissural neurons are incapable of inducing intracellular signaling downstream of netrin-1 and DCC. This includes DCC phosphorylation and MAPK activation, both of which are functionally involved in netrin-1-dependent axon outgrowth (Forcet et al., 2002; Meriane et al., 2004). Thus, the requirement for HS was demonstrated not only in terms of in vivo and in vitro axon outgrowth responses but also in terms of intracellular signaling mechanisms underlying these responses.

It should be emphasized that our results do not rule out a non-cell-autonomous role for HS in commissural axon pathfinding, namely regulation of the netrin-1 gradient in the ventral spinal cord. The two modes of HS action may coexist in the process of commissural axon pathfinding, as suggested by Pratt et al. (2006) in the context of retinal axon guidance at the optic chiasm. Nevertheless, it is noteworthy that the magnitude of the commissural axon phenotype in Wnt1-Cre; Ext $1^{\text {flox/flox }}$ embryos is approximately comparable with those of Netrin-1 ${ }^{-1-}$ and $D \mathrm{cc}^{-1-}$ mutants (Serafini et al., 1996; Fazeli et al., 1997). This observation suggests that the role of cell-autonomous HS is the predominant one.

Another question that could not be addressed in this study is whether HS is required for guidance molecules other than netrin-1. Although the phenotypical similarities strongly suggest a predominant role for HS in netrin-1/DCC-dependent pathfinding processes, the commissural axon phenotype of Wnt1$\mathrm{Cre}$; Ext $1^{\text {flox/flox }}$ mice is not exactly the same as that of Netrin $-1^{-/-}$ or $\mathrm{Dcc}^{-1-}$ mice. This may be attributable to the difference in the method of gene disruption used to generate these mutant mice, but it is also possible that the loss of HS may have affected other guidance molecules. For instance, Shh, which also binds to HS (albeit with a much lower affinity than that of netrin-1; see below), has been shown to act as an additional, netrin-1/DCCindependent guidance cue for spinal commissural axons (Charron et al., 2003). Defasciculation of the dorsal root entry zone (Fig. 6B) suggests that HS might also be involved in the pathfinding of sensory axons. Additional studies will be needed to deter- 

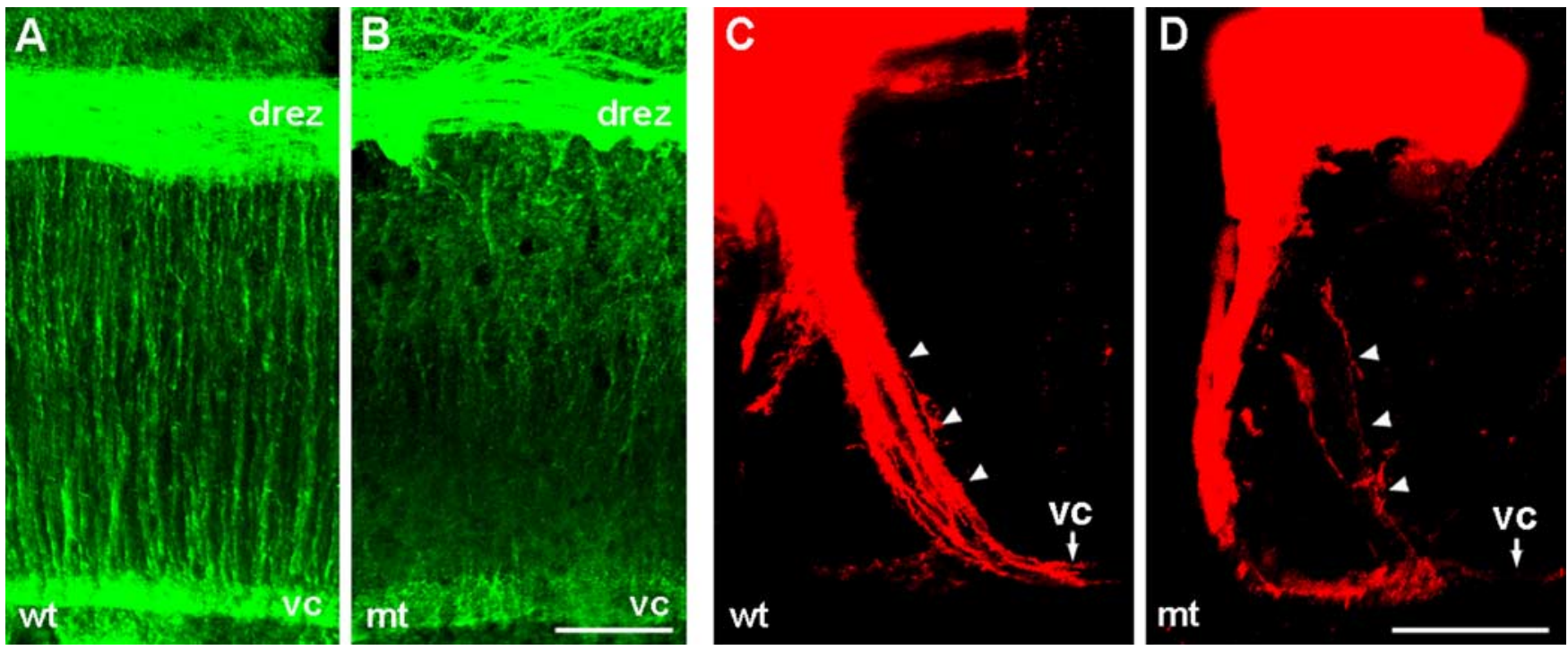

Figure 6. Commissural axons do not normally project into the ventral spinal cord in Wnt1-Cre;Ext floxfflox mice. $\boldsymbol{A}, \boldsymbol{B}$, Open-book view of whole-mount spinal cords stained with anti-TAG-

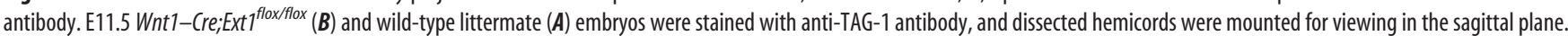

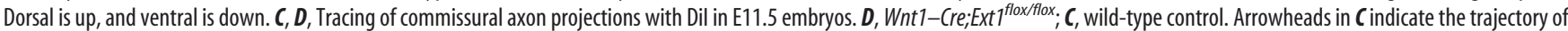

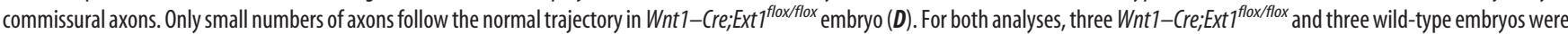
examined with similar results. drez, Dorsal root entry zone; vc, ventral commissure; wt, wild-type littermate; mt, Wnt1-Cre;Ext floxfflox embryos. Scale bars, $100 \mu \mathrm{m}$.

mine the full extent of the role of HS in axon guidance in the developing spinal cord.

The most likely molecular mechanism for cell-autonomous HS-dependent netrin-1/DCC signaling is that HS on the surface of commissural axons acts as a functional coreceptor for netrin-1. In fact, this notion is in agreement with a previous prediction based on the activity of an MET receptor tyrosine kinase-DCC chimera that there should be a coreceptor for netrin-1 (Stein et al., 2001). The coreceptor function of HS has been most extensively studied in terms of FGF/FGF receptor (FGFR) signaling (for review, see Ornitz, 2000; Mohammadi et al., 2005). It is believed that the ligand and the receptor associate with HS/heparin to form an active signaling FGF/FGFR complex (Pellegrini et al., 2000; Schlessinger et al., 2000; Mohammadi et al., 2005). Our present results suggest that a similar mechanism may operate in netrin-1/DCC signaling. Although detailed biochemical and structural experiments would be required to test this hypothesis, it is noteworthy that the FGF/FGFR and netrin-1/DCC signaling systems share at least two interesting biochemical features. First, both FGFs and netrin-1 bind heparin with very high affinity, requiring $>1.3 \mathrm{M} \mathrm{NaCl}$ for elution from heparin-Sepharose (Esch et al., 1985; Serafini et al., 1994). In comparison, other "heparin-binding" factors are of much lower affinity, being eluted from heparinSepharose with $<1.0 \mathrm{~m} \mathrm{NaCl}$ [e.g., Shh with $0.5-0.8 \mathrm{M} \mathrm{NaCl}$ (Rubin et al., 2002);
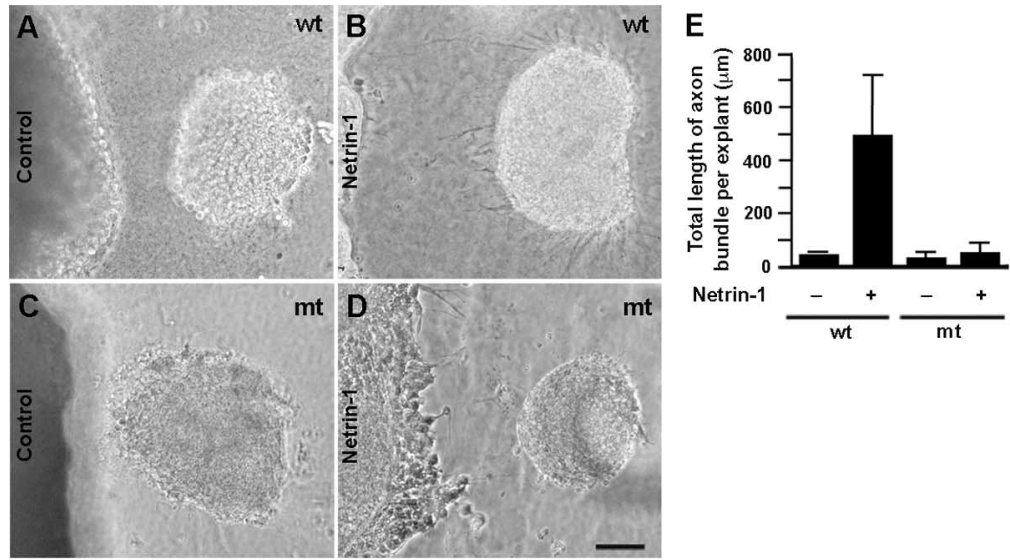

Netrin-1
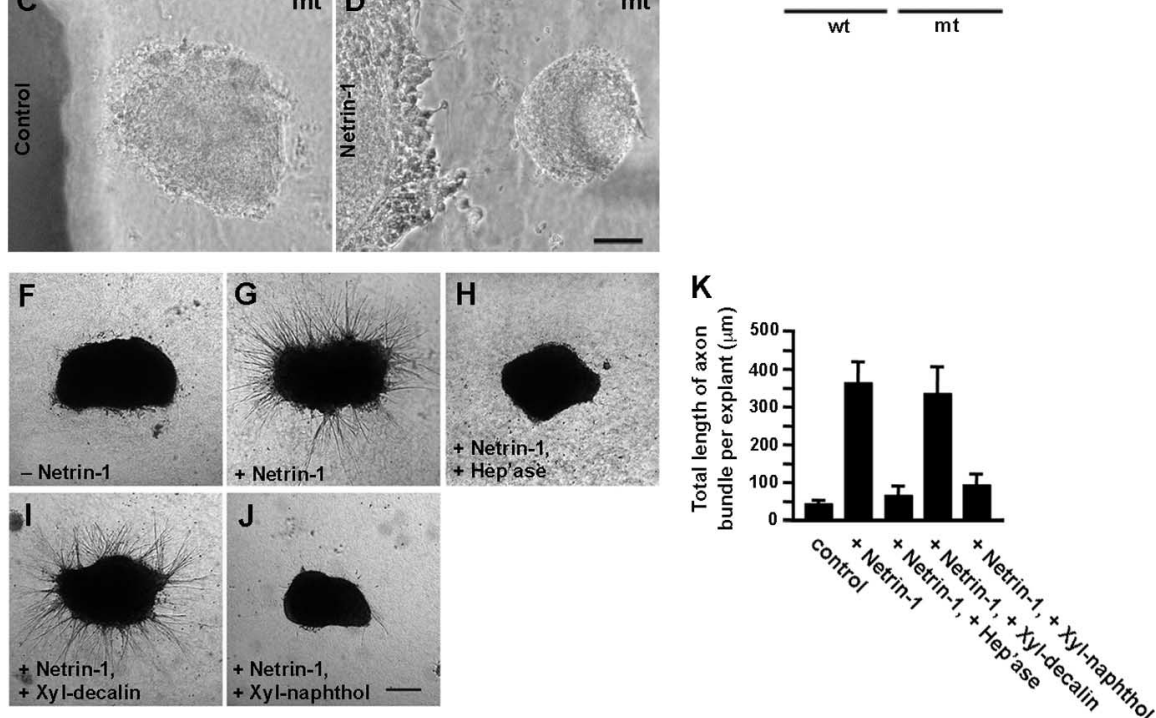

Figure 7. Effect of cell-autonomous loss of HS on netrin-1-mediated axon outgrowth. $A-E$, Axon outgrowth assays in collagen gels. E11.5 dorsal spinal cord explants from Wnt1-Cre; Ext $7^{\text {flox/flox }}(\mathrm{mt})$ and control (wt) embryos were cultured for $24 \mathrm{~h}$ with aggregates of mock-transfected (Control) or netrin-1-transfected (Netrin-1) HEK293T cells. $\boldsymbol{A}$, Wild-type explant with control aggregates; $\boldsymbol{B}$, wild-type explant with netrin-1-secreting aggregates; $\boldsymbol{C}$, mutant explant with control aggregates; $\boldsymbol{D}$, mutant explant with netrin-1-secreting aggregates. Scale bars, $100 \mu \mathrm{m}$. $\boldsymbol{E}$, Quantification of the total length of axon bundles per explant (mean $\pm S D ; n=10)$. $\boldsymbol{F}-\boldsymbol{K}$, Effect of enzymatic and chemical removal of HS on axon outgrowth elicited by soluble recombinant netrin-1 in E11.5 dorsal spinal cord explants. Explants were stimulated without $(\boldsymbol{F})$ or with $(\mathbf{G}-J) 500 \mathrm{ng} / \mathrm{ml} \mathrm{recombinant} \mathrm{netrin-1}$ after the following treatment: in $\boldsymbol{G}$ and $\boldsymbol{H}$, explants were treated without $(\boldsymbol{G})$ or with $(\boldsymbol{H})$ heparitinase; in $\boldsymbol{I}$ and $\boldsymbol{J}$, explants were treated with Xyl-decalin $(\boldsymbol{I})$ or Xyl-naphthol $(\boldsymbol{J})$. Note that axon outgrowth was inhibited by enzymatic removal with heparitinase $(\boldsymbol{H})$ and by chemical perturbation of $\mathrm{HS}$ with Xyl-naphthol $(J)$. Xyl-decalin, which does not perturb HS, shows no inhibitory effects on axon outgrowth $(I) . K$, Quantification of the total lengths of axon bundles per explant (mean $\pm S D ; n=16$ ). 
A

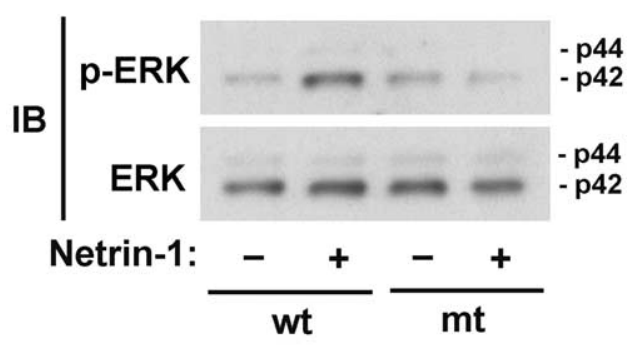

C
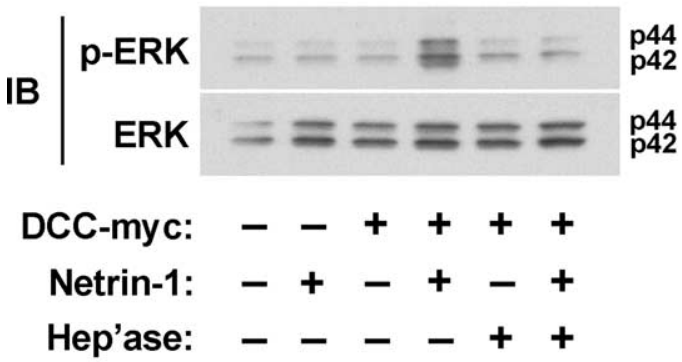

D
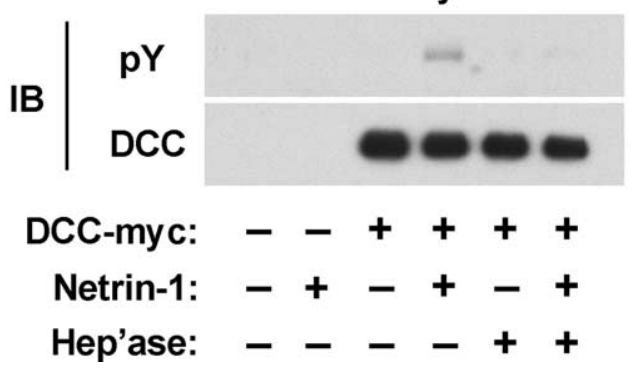

Figure 8. Effects of cell-autonomous loss of HS on netrin-1 downstream signaling. A-C, Analysis of netrin-1-dependent activation of the MAPK pathway. $A$, Commissural neurons dissociated from E11.5 Wnt1-Cre; Ext $7^{\text {flox/flox }}(\mathrm{mt})$ and control littermate (wt) embryos were stimulated without $(-)$ or with $(+) 500 \mathrm{ng} / \mathrm{ml}$ recombinant netrin-1 for $15 \mathrm{~min}$, and cell lysates were immunoblotted with anti-ERK1/2 (ERK) and anti-phospho-ERK1/2 (p-ERK) antibodies. B, Quantification of the results in $\boldsymbol{A}$. Levels of total ERK1/2 and phosphorylated-ERK1/2 normalized with respect to wild-type, untreated cells were shown (mean $\pm S D ; n=$ 4). C, Effect of HS removal on netrin-1-dependent activation of the MAPK pathway in HEK293T cells. HEK293T cells transfected with myc-tagged DCC (DCC-myc) were treated with heparitinase and netrin-1 in combinations shown in the figure. Cell lysates were immunoblotted with anti-phospho-ERK and anti-ERK (total) antibodies. D, Effect of $\mathrm{HS}$ removal on netrin-1-induced DCC phosphorylation in HEK293T cells. HEK293T cells transfected with myc-tagged DCC (DCC-myc) were treated with heparitinase and netrin-1 in combinations shown in the figure. DCC immunoprecipitated with anti-myc antibody was immunoblotted with antiphosphotyrosine (pY) and anti-DCC antibodies (DCC). E, Tyrosine phosphorylation of DCC in vivo. Lysate of E11.5 Wnt1-Cre; Ext $7^{\text {flox/flox }}(\mathrm{mt})$ and control (wt) spinal cords were immunoprecipitated with anti-DCC antibody, and the precipitated materials were immunoblotted with anti-DCC (DCC) and anti-phosphotyrosine $(\mathrm{pY})$ antibodies.

Wnt1 with 0.45-0.75 M (Bradley and Brown, 1990); Ig-neuregulin 1 with $0.5-0.7 \mathrm{M}$ (Falls et al., 1993); various chemokines with 0.4-0.9 M NaCl (Kuschert et al., 1999)]. Second, for both the FGF/FGFR and netrin-1/DCC systems, not only ligands but also receptors (i.e., FGF receptor and DCC, respectively) have affinity for heparin/HS (Bennett et al., 1997; Mohammadi et al., 2005). Thus, the biochemical property of the netrin-1/DCC system with regard to HS binding appears more similar to that of the FGF/ FGFR system than that of the other HS-binding factors. These two features might be the key that determines whether HS acts as obligatory coreceptors for a given signaling pathway.

In conclusion, this study establishes a physiological requirement for HS in netrin-1/DCC-mediated commissural axon path- finding. HS needs to be expressed on commissural neurons for them to transduce and respond to the chemoattractive stimulus of netrin-1. We suggest a model in which HSPGs on the surface of commissural axons associate with netrin-1 and DCC to form a signaling complex, thereby acting as a functional coreceptor. Future biochemical and structural studies will test this model and thereby elucidate the exact molecular mechanism whereby HS participates in netrin-1-mediated axon guidance.

\section{References}

Baeg GH, Selva EM, Goodman RM, Dasgupta R, Perrimon N (2004) The Wingless morphogen gradient is established by the cooperative action of Frizzled and Heparan Sulfate Proteoglycan receptors. Dev Biol 276:89-100.

Bennett KL, Bradshaw J, Youngman T, Rodgers J, Greenfield B, Aruffo A, Linsley PS (1997) Deleted in colorectal carcinoma (DCC) binds heparin via its fifth fibronectin type III domain. J Biol Chem 272:26940-26946.

Bouchard J, Moore S, Tritsch N, Roux P, Shekarabi M, Barker P, Kennedy T (2004) Protein kinase $\mathrm{A}$ activation promotes plasma membrane insertion of DCC from an intracellular pool: a novel mechanism regulating commissural axon extension. J Neurosci 24:3040-3050.

Bovolenta P, Dodd J (1990) Guidance of commissural growth cones at the floor plate in embryonic rat spinal cord. Development 109:435-447.

Bradley RS, Brown AM (1990) The protooncogene int- 1 encodes a secreted protein associated with the extracellular matrix. EMBO J 9:1569-1575.

Charron F, Stein E, Jeong J, McMahon AP, TessierLavigne M (2003) The morphogen sonic hedgehog is an axonal chemoattractant that collaborates with netrin-1 in midline axon guidance. Cell 113:11-23.

Colamarino SA, Tessier-Lavigne M (1995) The role of the floor plate in axon guidance. Annu Rev Neurosci 18:497-529.

Danielian PS, Muccino D, Rowitch DH, Michael SK, McMahon AP (1998) Modification of gene activity in mouse embryos in utero by a tamoxifen-inducible form of Cre recombinase. Curr Biol 8:1323-1326.

Del Rio J, Gonzalez-Billault C, Urena J, Jimenez E, Barallobre M, Pascual M, Pujadas L, Simo S, La Torre A, Wandosell F, Avila J, Soriano E (2004) MAP1B is required for Netrin 1 signaling in neuronal migration and axon guidance. Curr Biol 14:840-850.

Esch F, Baird A, Ling N, Ueno N, Hill F, Denoroy L, Klepper R, Gospodarowicz D, Bohlen P, Guillemin R (1985) Primary structure of bovine pituitary basic fibroblast growth factor (FGF) and comparison with the amino-terminal sequence of bovine brain acidic FGF. Proc Natl Acad Sci USA 82:6507-6511.

Esko JD, Lindahl U (2001) Molecular diversity of heparan sulfate. J Clin Invest 108:169-173.

Falls DL, Rosen KM, Corfas G, Lane WS, Fischbach GD (1993) ARIA, a protein that stimulates acetylcholine receptor synthesis, is a member of the neu ligand family. Cell 72:801-815.

Fazeli A, Dickinson SL, Hermiston ML, Tighe RV, Steen RG, Small CG, Stoeckli ET, Keino-Masu K, Masu M, Rayburn H, Simons J, Bronson RT, Gordon JI, Tessier-Lavigne M, Weinberg RA (1997) Phenotype of mice lacking functional Deleted in colorectal cancer (Dcc) gene. Nature 386:796-804. 
Forcet C, Stein E, Pays L, Corset V, Llambi F, Tessier-Lavigne M, Mehlen P (2002) Netrin-1-mediated axon outgrowth requires deleted in colorectal cancer-dependent MAPK activation. Nature 417:443-447.

Fritz TA, Lugemwa FN, Sarkar AK, Esko JD (1994) Biosynthesis of heparan sulfate on $\beta$-D-xylosides depends on aglycone structure. J Biol Chem 269:300-307.

Fujise M, Takeo S, Kamimura K, Matsuo T, Aigaki T, Izumi S, Nakato H (2003) Dally regulates Dpp morphogen gradient formation in the Drosophila wing. Development 130:1515-1522.

Holt CE, Dickson BJ (2005) Sugar codes for axons? Neuron 46:169-172.

$\mathrm{Hu} \mathrm{H}$ (2001) Cell-surface heparan sulfate is involved in the repulsive guidance activities of Slit2 protein. Nat Neurosci 4:695-701.

Inatani M, Irie F, Plump AS, Tessier-Lavigne M, Yamaguchi Y (2003) Mammalian brain morphogenesis and midline axon guidance require heparan sulfate. Science 302:1144-1146.

Irie F, Okuno M, Pasquale EB, Yamaguchi Y (2005) EphrinB-EphB signalling regulates clathrin-mediated endocytosis through tyrosine phosphorylation of synaptojanin 1. Nat Cell Biol 7:501-509.

Kantor DB, Chivatakarn O, Peer KL, Oster SF, Inatani M, Hansen MJ, Flanagan JG, Yamaguchi Y, Sretavan DW, Giger RJ, Kolodkin AL (2004) Semaphorin $5 \mathrm{~A}$ is a bifunctional axon guidance cue regulated by heparan and chondroitin sulfate proteoglycans. Neuron 44:961-975.

Keino-Masu K, Masu M, Hinck L, Leonardo ED, Chan SS, Culotti JG, TessierLavigne M (1996) Deleted in Colorectal Cancer (DCC) encodes a netrin receptor. Cell 87:175-185.

Kennedy TE, Serafini T, de la Torre JR, Tessier-Lavigne M (1994) Netrins are diffusible chemotropic factors for commissural axons in the embryonic spinal cord. Cell 78:425-435.

Kramer ER, Knott L, Su F, Dessaud E, Krull CE, Helmbacher F, Klein R (2006) Cooperation between GDNF/Ret and ephrinA/EphA4 signals for motor-axon pathway selection in the limb. Neuron 50:35-47.

Kuschert GS, Coulin F, Power CA, Proudfoot AE, Hubbard RE, Hoogewerf AJ, Wells TN (1999) Glycosaminoglycans interact selectively with chemokines and modulate receptor binding and cellular responses. Biochemistry 38:12959-12968.

Lander AD, Selleck SB (2000) The elusive functions of proteoglycans: in vivo veritas. J Cell Biol 148:227-232.

Lee JS, Chien CB (2004) When sugars guide axons: insights from heparan sulphate proteoglycan mutants. Nat Rev Genet 5:923-935.

Meriane M, Tcherkezian J, Webber CA, Danek EI, Triki I, McFarlane S, Bloch-Gallego E, Lamarche-Vane N (2004) Phosphorylation of DCC by Fyn mediates Netrin-1 signaling in growth cone guidance. J Cell Biol 167:687-698.

Mohammadi M, Olsen SK, Goetz R (2005) A protein canyon in the FGFFGF receptor dimer selects from an a la carte menu of heparan sulfate motifs. Curr Opin Struct Biol 15:506-516.

Ornitz DM (2000) FGFs, heparan sulfate and FGFRs: complex interactions essential for development. BioEssays 22:108-112.

Pellegrini L, Burke DF, von Delft F, Mulloy B, Blundell TL (2000) Crystal structure of fibroblast growth factor receptor ectodomain bound to ligand and heparin. Nature 407:1029-1034.
Perrimon N, Bernfield M (2000) Specificities of heparan sulphate proteoglycans in developmental processes. Nature 404:725-728.

Pratt T, Conway CD, Tian NML, Price DJ, Mason JO (2006) Heparan sulphation patterns generated by specific heparan sulfotransferase enzymes direct distinct aspects of retinal axon guidance at the optic chiasm. J Neurosci 26:6911-6923.

Rapraeger AC, Krufka A, Olwin BB (1991) Requirement of heparan sulfate for bFGF-mediated fibroblast growth and myoblast differentiation. Science 252:1705-1708.

Rubin JB, Choi Y, Segal RA (2002) Cerebellar proteoglycans regulate sonic hedgehog responses during development. Development 129:2223-2232.

Schlessinger J, Plotnikov AN, Ibrahimi OA, Eliseenkova AV, Yeh BK, Yayon A, Linhardt RJ, Mohammadi M (2000) Crystal structure of a ternary FGF-FGFR-heparin complex reveals a dual role for heparin in FGFR binding and dimerization. Mol Cell 6:743-750.

Serafini T, Kennedy TE, Galko MJ, Mirzayan C, Jessell TM, Tessier-Lavigne M (1994) The netrins define a family of axon outgrowth-promoting proteins homologous to C. elegans UNC-6. Cell 78:409-424.

Serafini T, Colamarino SA, Leonardo ED, Wang H, Beddington R, Skarnes WC, Tessier-Lavigne M (1996) Netrin-1 is required for commissural axon guidance in the developing vertebrate nervous system. Cell 87:1001-1014.

Soriano P (1999) Generalized lacZ expression with the ROSA26 Cre reporter strain. Nat Genet 21:70-71.

Stein E, Zou Y, Poo M, Tessier-Lavigne M (2001) Binding of DCC by netrin-1 to mediate axon guidance independent of adenosine A2B receptor activation. Science 291:1976-1982.

Tessier-Lavigne M, Placzek M, Lumsden AG, Dodd J, Jessell TM (1988) Chemotropic guidance of developing axons in the mammalian central nervous system. Nature 336:775-778.

The I, Bellaiche Y, Perrimon N (1999) Hedgehog movement is regulated through tout velu-dependent synthesis of a heparan sulfate proteoglycan. Mol Cell 4:633-639.

Toba Y, Horie M, Sango K, Tokashiki A, Matsui F, Oohira A, Kawano H (2002) Expression and immunohistochemical localization of heparan sulphate proteoglycan $\mathrm{N}$-syndecan in the migratory pathway from the rat olfactory placode. Eur J Neurosci 15:1461-1473.

Tronche F, Kellendonk C, Kretz O, Gass P, Anlag K, Orban PC, Bock R, Klein R, Schütz G (1999) Disruption of the glucocorticoid receptor gene in the nervous system results in reduced anxiety. Nat Genet 23:99-103.

Yayon A, Klagsbrun M, Esko JD, Leder P, Ornitz DM (1991) Cell surface, heparin-like molecules are required for binding of basic fibroblast growth factor to its high affinity receptor. Cell 64:841-848.

Yu K, Xu J, Liu Z, Sosic D, Shao J, Olson E, Towler D, Ornitz D (2003) Conditional inactivation of FGF receptor 2 reveals an essential role for FGF signaling in the regulation of osteoblast function and bone growth. Development 130:3063-3074.

Zak BM, Crawford BE, Esko JD (2002) Hereditary multiple exostoses and heparan sulfate polymerization. Biochim Biophys Acta 1573:346-355. 